\title{
PATHWAYS OF GLYCOGEN FORMATION IN LIVER AND SKELETAL MUSCLE IN FED AND FASTED RATS ${ }^{1}$
}

\author{
By PAUL A. MARKS AND PHILIP FEIGELSON \\ (From the Departments of Medicine and Biochemistry, College of Physicians and Surgeons, \\ Columbia University, New York, N. Y.)
}

(Submitted for publication March 22, 1957; accepted April 25, 1957)

It is now well established that most animal tissues contain enzymes of a non-glycolytic pathway, the pentose phosphate pathway, in addition to those involved in anaerobic glycolysis $(1,2)$. Skeletal muscle, however, appears to contain glucose-6-phosphate dehydrogenase and 6-phosphogluconic dehydrogenase, enzymes of this alternate pathway, in relatively low concentrations.

The relative importance of the glycolytic, pentose phosphate and tricarboxylic acid pathways in the conversion of glucose to $\mathrm{CO}_{2}$ in liver and in muscle has been the subject of previous in vitro studies. Bloom, Stetten and Stetten (3) and Agranoff, Brady and Colodzin (4) found that glucose oxidation proceeded by both glycolytic and non-glycolytic pathways in rat liver slices, while in muscle all the $\mathrm{CO}_{2}$ arising from glucose could be accounted for via glycolysis. In studies with intact animals, a number of investigators have obtained evidence for the participation of both the glycolytic and pentose phosphate pathways in the formation of glycogen (5-8) and of nucleic acid ribose $(8,9)$, and in the oxidation of glucose to $\mathrm{CO}_{2}(10)$ in liver.

The present study was designed to evaluate in vivo the relative importance of the various pathways in the formation of glycogen in skeletal muscle and liver of intact rats. The pattern of isotope incorporation into the individual carbon atoms of the glucose of glycogen, when 2-C14-glucose was employed as the tracer source, has been used as an indication of possible differences in liver and muscle glycogen formation. In view of the fact that fasting can markedly deplete the glycogen of liver (11), but not of muscle, and can be associated with definite changes in overall glucose metabolism (12), observations were made on both fasted and fed rats. Striking differences

1 This work was supported, in part, by a grant from the National Cancer Institute, U. S. Public Health Service, and Grant G-1294 from the National Science Foundation. were found between the patterns of tracer incorporation into the glycogen of liver and that of muscle. In addition, the animals' prior dietary status appeared to influence the pathways of glycogen formation.

\section{METHODS}

Male rats of the Wistar strain, weighing between 200 and $275 \mathrm{Gm}$., were fed a nutritionally complete semisynthetic diet (13). In the studies with fasted rats, all food was withdrawn for a 36-hour period prior to isotope administration. All animals were offered water ad libitum. One hour prior to the intraperitoneal injection of about $15 \mu \mathrm{c}$. of $2-\mathrm{C}^{14}-\mathrm{glucose}$ in $0.6 \mathrm{ml}$. of isotonic saline, each animal was given by stomach tube 1.0 ml. of a 25 per cent glucose solution per $100 \mathrm{Gm}$. of body weight. The rats were sacrificed by a blow on the head and exsanguinated 6 hours after the administration of the isotope. Liver and skeletal muscle were promptly removed by free-hand dissection. Glycogen was isolated from liver and from muscle by the method of Stetten and Boxer (14). Glucose was obtained by hydrolysis of glycogen with $1 \mathrm{~N} \mathrm{H}_{2} \mathrm{SO}_{4}$ as described by Topper and Hastings (15). Reducing sugar was determined by the method of Somogyi (16). Glucose was degraded by fermentation with Leuconostoc mesenteroides, which has been shown by Gunsalus and Gibbs (17) to yield $\mathrm{CO}$, from $\mathrm{C}-1,2$ ethanol from $\mathrm{C}-2$ and $\mathrm{C}-3$, and lactic acid from C-4, C-5 and C-6. The details of the degradation procedure have been described previously (13). All carbon atoms obtained by the degradation of the glucose molecules were converted to barium carbonate and radioactivity assayed at infinite thickness in a windowless flow counter with an absolute counting efficiency of 12 per cent. A sufficient number of counts was recorded to insure a standard error of less than five per cent. The specific activity of the glycogen samples was determined by plating and counting the glycogen as such. Radioactivities are expressed in millimicrocuries per mg. by employing an experimentally determined conversion factor.

The 2-C $\mathrm{C}^{26}$-glucose employed in this study was obtained from Dr. H. Isbell, of the National Bureau of Standards.

2 The symbol $\mathrm{C}$ refers to carbon atom and the number following to the position of the carbon atom in the glucose molecule. 
TABLE I

Incorporation of $C^{14}$ into glycogen of liver and muscle following intraperitoneal injection of 2-C ${ }^{\mathbf{1 4}}$-glucose

\begin{tabular}{|c|c|c|c|c|}
\hline \multirow{2}{*}{$\begin{array}{l}\text { Experi- } \\
\text { ment } \\
\text { no. }\end{array}$} & \multirow[b]{2}{*}{$\begin{array}{c}\text { Dietary } \\
\text { status }\end{array}$} & \multicolumn{2}{|c|}{ Specific activity } & \multirow[b]{2}{*}{$\begin{array}{l}\text { Ratio } \\
\text { L/M }\end{array}$} \\
\hline & & $\begin{array}{l}\text { Liver } \\
\text { (L) }\end{array}$ & $\underset{\text { (M) }}{\text { Muscle }}$ & \\
\hline $\begin{array}{l}1 \\
2 \\
3 \\
4 \\
5\end{array}$ & $\begin{array}{l}\text { Fasted } \\
\text { Fasted } \\
\text { Fasted } \\
\text { Fed } \\
\text { Fed }\end{array}$ & $\begin{array}{l}2.43 \\
2.27 \\
3.18 \\
0.14 \\
0.20\end{array}$ & $\begin{array}{l}1.51 \\
1.35 \\
1.94 \\
0.89 \\
1.50\end{array}$ & $\begin{array}{l}1.61 \\
1.68 \\
1.64 \\
0.16 \\
0.13\end{array}$ \\
\hline
\end{tabular}

* Millimicrocuries per mg. of glycogen.

\section{RESULTS}

\section{Incorporation of $C^{14}$-glucose into glycogen}

In the fasted animals, the specific activity of the glycogen of liver exceeded that of muscle, while in fed animals, the muscle glycogen had a higher specific activity than did the liver glycogen (Table I). These findings indicate that a greater fraction of liver glycogen was derived from the injected labeled glucose in the fasted than in the fed animals. On the other hand, the specific activity of muscle glycogen was little affected by the animals' dietary status. These findings are consistent with the well-established fact that fasting depletes the liver of glycogen but has little effect upon the level of the glycogen of muscle.

Pattern of $C^{14}$ incorporation into glycogen of liver

In the experiments with fasted animals, 61.1 to 72.0 per cent of the total activity in the glucose of liver glycogen was in C-2 (Experiments 1 to 3, Table II), while in the studies with fed rats, 74.1 and 79.0 per cent of the total activity was incorporated into C-2 (Experiments 4 and 5, Table III). Degradation of the administered 2-C $\mathrm{C}^{14}$ glucose revealed that 99.4 per cent of the total activity was originally in C-2. In all of these experiments, the pattern of $\mathrm{C}^{14}$ distribution revealed that isotope initially in C-2 contributed tracer to all the other carbons of glucose. In both the fed and fasted animals, the greatest migration from C-2 was to $\mathrm{C}-1$. The specific activity of $\mathrm{C}-1$ relative to $\mathrm{C}-2$ was greater in the fasted animals than in the fed animals. It may be noted that in each instance $\mathrm{C}-1$ possessed a considerably higher specific activity than C- 6 and that this difference, too, was considerably more striking in the experiments with fasted animals. Of the amount of isotope that was randomized from $\mathrm{C}-2$ to the positions other than C-1, a somewhat greater amount was incorporated into $\mathrm{C}-5$ than into $\mathrm{C}-3, \mathrm{C}-4$, or $\mathrm{C}-6$.

\section{Pattern of $C^{14}$ incorporation into glycogen of muscle}

In the glucose of muscle glycogen isolated from fasted rats, 98.0 to 98.7 per cent of the total isotope incorporated was in C-2 (Experiments 1 to 3, Table II). When fed rats were employed, 90.1 and 93.1 per cent of the total radioactivity incorporated into the glycogen of muscle was in C-2 (Experiments 4 and 5, Table III). In all of the experiments, the randomization of $\mathrm{C}^{14}$ from $\mathrm{C}-2$

TABLE II

$C^{14}$ distribution in glucose of glycogen isolated from liver and skeletal muscle of fasted rats following intraperitoneal administration of 2-C14-glucose

\begin{tabular}{|c|c|c|c|c|c|c|c|}
\hline \multirow{2}{*}{$\begin{array}{l}\text { Experiment } \\
\text { no. }\end{array}$} & \multirow[b]{2}{*}{ Tissue } & \multicolumn{6}{|c|}{ Per cent of total activity* } \\
\hline & & $\mathrm{C}-1$ & C-2 & $\mathrm{C}-3$ & C-4 & C.5 & C-6 \\
\hline \multirow[t]{2}{*}{1} & Liver & 13.3 & \multirow{2}{*}{$\begin{array}{l}72.0 \\
(20.48) \\
98.7 \\
(7.11)\end{array}$} & 3.4 & 3.4 & 5.0 & 2.9 \\
\hline & Muscle & 0.4 & & 0.2 & 0.3 & 0.2 & 0.2 \\
\hline \multirow[t]{2}{*}{2} & Liver & 16.2 & \multirow{2}{*}{$\begin{array}{l}\mathbf{6 5 . 4} \\
(5.62) \\
98.0 \\
(1.68)\end{array}$} & 4.2 & 4.7 & 5.6 & 3.9 \\
\hline & Muscle & 0.5 & & 0.3 & 0.3 & 0.4 & 0.5 \\
\hline \multirow[t]{2}{*}{3} & Liver & 19.7 & \multirow{2}{*}{$\begin{array}{c}61.1 \\
(10.33) \\
98.8 \\
(10.57)\end{array}$} & 5.4 & 4.9 & 6.9 & 2.0 \\
\hline & Muscle & 0.3 & & 0.2 & 0.3 & 0.3 & 0.1 \\
\hline
\end{tabular}

* Specific activity of the most radioactive carbon in each compound is indicated in parentheses in millimicrocuries per mg. carbon. The values for specific activity are not corrected for carrier glucose which was added for purposes of degradation. The absolute specific activities of the glucose carbons of liver cannot, therefore, be compared with those of muscle. 
TABLE III

C" distribution in glucose of glycogen isolated from liver and skeletal muscle of fed rats following intraperitoneal administration of 2-C $C^{14}$-glucose

\begin{tabular}{|c|c|c|c|c|c|c|c|}
\hline \multirow{2}{*}{$\begin{array}{l}\text { Experiment } \\
\text { no. }\end{array}$} & \multirow[b]{2}{*}{ Tissue } & \multicolumn{6}{|c|}{ Per cent of total activity* } \\
\hline & & $\mathrm{C}_{1}$ & $\mathrm{C}-2$ & $\mathrm{C}-3$ & $\mathrm{C}-4$ & C-5 & C-6 \\
\hline \multirow[t]{2}{*}{4} & Liver & 8.4 & \multirow{2}{*}{$\begin{array}{l}74.1 \\
(0.91) \\
90.1 \\
(1.57)\end{array}$} & 5.0 & 4.2 & 5.0 & 3.3 \\
\hline & Muscle & 3.2 & & 1.7 & 1.7 & 1.7 & 1.6 \\
\hline \multirow[t]{2}{*}{5} & Liver & 5.7 & \multirow{2}{*}{$\begin{array}{l}79.0 \\
(0.52) \\
93.1 \\
(7.39)\end{array}$} & 3.4 & 4.1 & 4.5 & 3.3 \\
\hline & Muscle & 2.3 & & 1.3 & 1.0 & 1.1 & 1.1 \\
\hline
\end{tabular}

* Specific activity of the most radioactive carbon in each compound is indicated in parentheses in millimicrocuries per mg. carbon. The values for specific activity are not corrected for carrier glucose which was added for purposes of degradation. The absolute specific activities of the glucose carbons of liver cannot, therefore, be compared with those of muscle.

to $\mathrm{C}-1$, or to the other carbon atoms of glucose, was much less in muscle glycogen than in liver glycogen.

\section{DISCUSSION}

In evaluating the present data in terms of the known intermediary reactions which may be involved in the formation of glycogen in liver and muscle, the following possible reaction sequences need be considered $(18-20): 1)$ 2-C ${ }^{14}$-glucose may be incorporated directly into the glycogen molecule essentially as an intact 6-carbon unit via glucose-6-phosphate and glucose-1-phosphate, so that the label will be exclusively in $\mathrm{C}-2$. 2) The reversible conversion of glucose-6-phosphate to the triose phosphates with isomerization at the level of dihydroxyacetone phosphate and 3-phospho- glyceraldehyde would yield glucose labeled in C-2 and C-5. 3) Conversion of glucose to $\mathrm{CO}_{2}$ via glycolysis (Embden-Meyerhof) and the tricarboxylic acid cycle and the subsequent reincorporation of $\mathrm{CO}_{2}$ into glucose by a reversal of these reactions would lead to randomization of isotope initially in C-2 of glucose to all the other carbon atoms of glucose (21). 4) The oxidative decarboxylation of 2-C ${ }^{14}$-glucose-6-phosphate to ribulose-5-phosphate by the reactions indicated in Figure 1 would yield $1-C^{14}$-pentose phosphate. 1-C ${ }^{14}$-pentose phosphate may be then converted to $1-C^{14}$-hexose phosphate via the transketolase reaction (Figure 2). 5) The reversible reactions catalyzed by the enzymes transketolase and transaldolase would result in $1,3-C^{14}$-hexose phosphate (Figure 3). (a)<smiles>CCCCC(O)C(O)C(O)C(O)CO</smiles>

(b) (c)

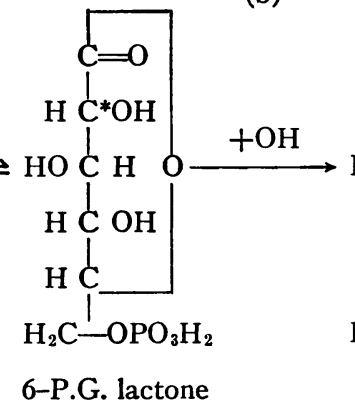

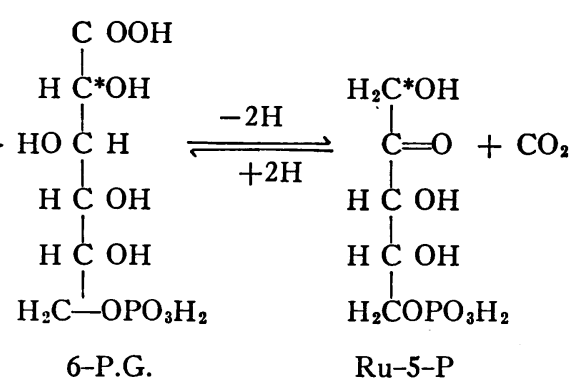

Fig. 1. Conversion of Glucose-6-Phosphate to Ribulose-5-Phosphate

(a) The oxidation of glucose-6-phosphate $(G-6-P)$ to 6-phosphogluconolactone (6-P.G. lactone) involves the reduction of triphosphopyridine nucleotide (TPN) and is catalyzed by the enzyme, glucose-6-phosphate dehydrogenase. (b) The conversion of 6-P.G. lactone to 6-phosphogluconate (6-P.G.) is catalyzed by the enzyme, lactonase. (c) The oxidative decarboxylation of 6-P.G. to ribulose-5-phosphate plus $\mathrm{CO}_{2}$ involves the reduction of TPN and is catalyzed by the enzyme, 6-phosphogluconic dehydrogenase. The course of the tracer initially in C-2 of glucose is indicated by the asterisk $\left(^{*}\right)$ in this Figure and Figures 2 and 3. 


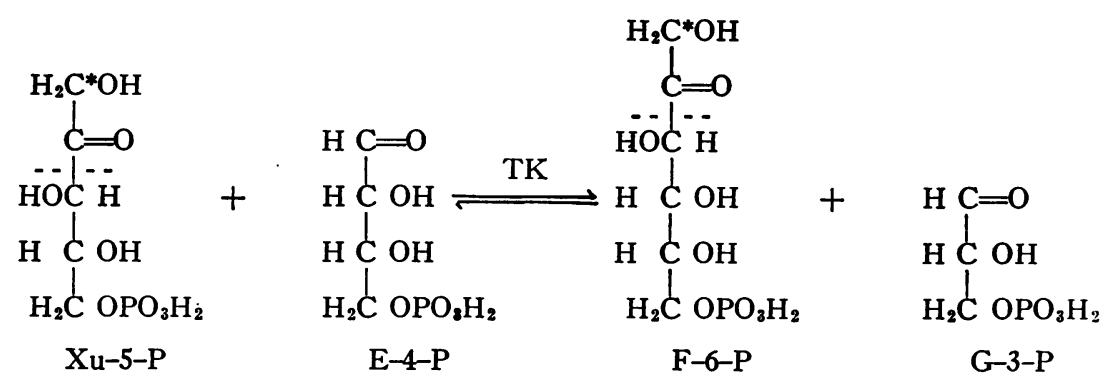

Fig. 2. Reaction Catalyzed by the Enzyme, Transketolase (TK)

Abbreviations: $\mathrm{Xu}-5-\mathrm{P}$, xylulose-5-phosphate; E-4-P, erythrose-4-phosphate ; F-6-P, fructose-6-phosphate; G-3-P, glyceraldehyde-3-phosphate. The broken line indicates the group transfer involved in this reaction.

Examination of the pattern of isotope incorporation into liver glycogen, in both fed and fasted rats, reveals that the predominant labeling was in C-2. This finding suggests that the primary pathway of glycogen formation from glucose was by direct incorporation of the administered intact 6-carbon unit (reaction sequence 1 indicated above). However, the striking asymmetric labeling of $\mathrm{C}-1$ is compatible with a significant formation of hexose from pentose via the pentose phosphate pathway (reaction sequences 4 and 5 indicated above, Figures 1 to 3 ). Fasting appeared to be associated with a greater migration of tracer from C-2 to C-1, which suggests that the pentose phosphate pathway is proportionately more important in the fasting state.

The finding of a higher specific activity of C-1 relative to C-3 in the glucose of hepatic glycogen is not consistent with hexose phosphate formation from pentose phosphate solely by the reaction sequence catalyzed by transketolase and transaldolase (reaction sequence 5 indicated above, Figure 3 ). In this reaction sequence, $1-\mathrm{C}^{14}$-pentose, which may be derived from
2-C ${ }^{14}$-glucose by oxidative decarboxylation, would yield hexose phosphate labeled equally in C-1 and $\mathrm{C}-3$. On the other hand, the reaction catalyzed by transketolase alone (Figure 2) could account for hexose phosphate labeled more heavily in $\mathrm{C}-1$ than in C-3. Transketolase may catalyze an exchange reaction in which the top two carbon atoms of xylulose-5-phosphate equilibrate with the top two carbon atoms of fructose-6-phosphate (Figure 2). In this manner, $1-\mathrm{C}^{14}$-pentose phosphate could yield 1-C14-hexose phosphate, without necessarily effecting a net synthesis of either sugar.

The randomization of isotope to positions 4 through 6 of glucose, with a predominance of labeling in C-5, is compatible with some contribution to hepatic glycogen formation by the reversible reactions of anaerobic glycolysis and the tricarboxylic acid cycle.

In skeletal muscle, the direct incorporation of administered glucose into glycogen appeared to be the dominant pathway. The minimal asymmetric labeling of $\mathrm{C}-1$ of muscle glycogen suggests that the oxidative decarboxylation of 2-C ${ }^{14}$-glucose-6phosphate to yield 1-C $\mathrm{C}^{14}$-pentose phosphate oc-

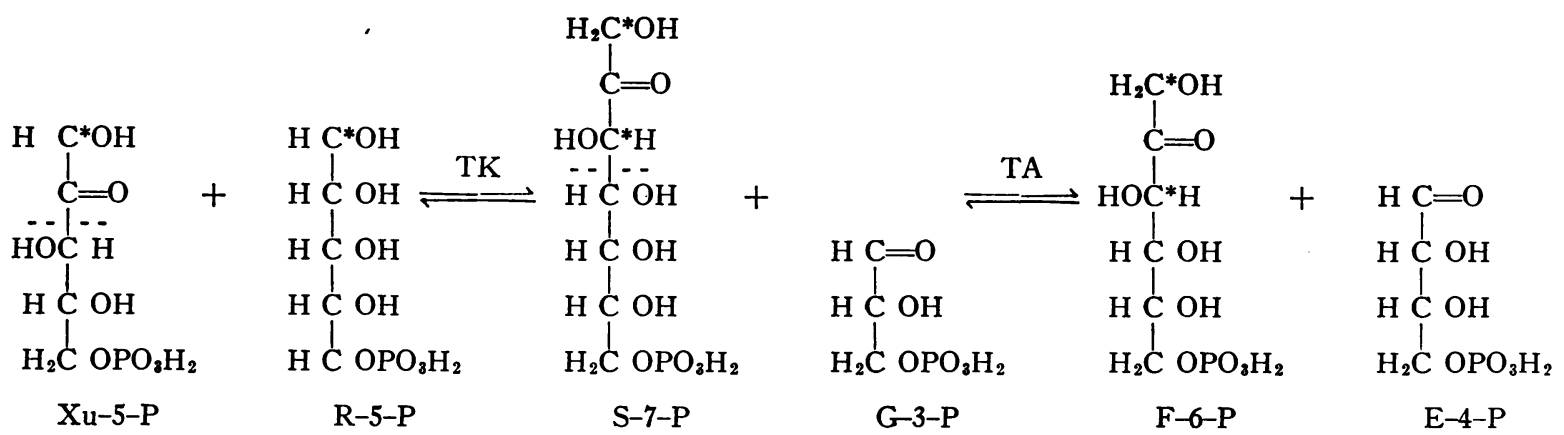

Fig. 3. Reactions Catalyzed by the Enzymes, Transketolase (TK) and Transaldolase (TA)

Abbreviations: R-5-P, ribose-5-phosphate; S-7-P, sedoheptulose-7-phosphate. The broken lines indicate the group transfers involved in these reactions. 
curs to a very limited extent, if at all, in skeletal muscle. In the absence of 1-C ${ }^{14}$-pentose phosphate formation, even though transketolase may be present in skeletal muscle (2), no labeling of C-1 of the glucose of glycogen may be expected. This finding, thus, presents in vivo evidence which is compatible with in vitro observations that skeletal muscle, in contrast to liver, possesses the enzymes glucose-6-phosphate dehydrogenase and 6-phosphogluconic dehydrogenase in low concentration $(1,2)$. The possibility exists that the minor amount of tracer incorporated into positions other than C-2 is not a result of muscle metabolism, but reflects the incorporation of glucose originating from the liver. In fed animals, endogenous glucose output might be expected to be greater than in fasted animals and this may be a factor contributing to the somewhat increased randomization of isotope in the glucose of muscle glycogen in the fed as compared with fasted animals.

In previous experiments, Cook and Lorber (22) and Hers (23), employing $1-\mathrm{C}^{14}$-glucose as the tracer source, found that hepatic glycogen was predominantly labeled in $\mathrm{C}-1$. These authors concluded that glucose is incorporated into hepatic glycogen essentially as an intact 6-carbon unit which does not pass through the pentose phosphate pathway reactions. The failure of these earlier studies to provide evidence for the role of the pentose phosphate pathway in the formation of glucose of hepatic glycogen would seem to be attributable to the use of $1-\mathrm{C}^{14}$-glucose as the isotope source. 1-C $\mathrm{C}^{14}$-glucose could not be expected to detect either a participation of the sequence of reactions involving oxidative decarboxylation of glucose-6-phosphate, in which the $\mathrm{C}^{14}$ would be converted to $\mathrm{CO}_{2}$, or the reversible transketolase reaction, in which the $\mathrm{C}^{14}$ would remain in $\mathrm{C}-1$ (Figures 1 and 2).

The present evidence for a significant role of the pentose phosphate pathway in the formation of the glucose of hepatic glycogen but not of skeletal muscle glycogen is not entirely in accord with the recent findings of Bloom, Eisenberg and Stetten (6). These investigators, employing $2-\mathrm{C}^{14}$-glucose as the tracer source and comparing the isotope distribution in carbons 1 and 6 of glucose of glycogen, found that the asymmetric incorporation of isotope into C-1 was more striking in muscle than in liver glycogen and in three of four ex- periments there was little or no preferential labeling of $\mathrm{C}-1$ in liver. There are experimental differences between these earlier experiments and the present ones, such as the interval between carrier and isotopic glucose administration to the animal and duration of the experiment, which may account for certain of the disparities between their observations and those of this study. The present findings, however, appear to be more consistent with the observed distribution of the enzymes of the pentose phosphate pathway and the studies of glucose oxidation to $\mathrm{CO}_{2}$ in liver and muscle.

It should be noted that the present isotope data do not permit precise quantitative estimates of the alternative pathways of glucose formation in terms of net synthesis or exchange reactions. Nevertheless, the data indicate that under the present experimental conditions in the liver of intact rats, the hexose precursor of glycogen is in equilibrium via the transketolase reaction, with pentose derived, at least in part, by oxidative decarboxylation. In skeletal muscle little or no hexose appears to be derived via pentose phosphate formed by oxidative decarboxylation of hexose phosphate. In addition, fasting was associated with a proportionately greater incorporation into liver glycogen but not into muscle glycogen of hexose equilibrated via the oxidative decarboxylation and transketolase reactions.

\section{SUM MARY}

Fasted and fed rats were given 2-C ${ }^{14}$-glucose by intraperitoneal injection; the glucose was isolated from the glycogen of liver and skeletal muscle and degraded to determine the $\mathrm{C}^{14}$ incorporation into each of the carbon atoms of the hexose.

In the glucose of liver glycogen, the predominant labeling was in C-2. An appreciable migration of tracer from C-2 to C-1 was observed with a lesser randomization of isotope to the other carbon positions of glucose. Fasting was associated with an increase in the specific activity of C-1 relative to C-2.

In the glucose of skeletal muscle glycogen from fasted rats, tracer was present essentially only in C-2. In the studies with fed animals, somewhat greater randomization of isotope occurred, with C-1 being more heavily labeled than C-3 through C-6. 
These data have been interpreted in terms of the known alternative routes of glucose utilization. It is concluded that, in liver, the pentose phosphate pathway contributes to the formation of glycogen glucose and that this is more apparent in the fasted than in the fed animal. In contrast, the glycogen of skeletal muscle appears to be derived almost entirely from glucose by direct incorporation of the intact administered 6-carbon unit, either in the fed or fasted states.

\section{ACKNOWLEDGMENT}

The authors are grateful to Mrs. Ellen Zablow for her technical assistance.

\section{REFERENCES}

1. Horecker, B. L., The metabolism of pentose and triose phosphates in Phosphorus Metabolism, Vol. 1, W. D. McElroy and B. Glass, Eds. Baltimore, The Johns Hopkins Press, 1951, p. 117.

2. Glock, G. E., and McLean, P., Levels of enzymes of the direct oxidative pathway of carbohydrate metabolism in mammalian tissues and tumours. Biochem. J., 1954, 56, 171.

3. Bloom, B., Stetten, M. R., and Stetten, D., Evaluation of catabolic pathways of glucose in mammalian systems. J. Biol. Chem., 1953, 204, 681.

4. Agranoff, B. W., Brady, R. O., and Colodzin, M., Differential conversion of specifically labeled glucose to $\mathrm{C}^{14} \mathrm{O}_{2}$. J. Biol. Chem., 1954, 211, 773.

5. Bernstein, I. A., Lentz, K., Malm, M., Schambye, P., and Wood, H. G., Degradation of glucose-C $\mathrm{C}^{34}$ with Leuconostoc mesenteroides: alternate pathways and tracer patterns. J. Biol. Chem., 1955, 215, 137.

6. Bloom, B., Eisenberg, F., and Stetten, D., Occurrence of non-Embden-Meyerhof pathways in the intact rat. J. Biol. Chem., 1956, 222, 301.

7. Hiatt, H. H., Glycogen formation via the pentose phosphate pathway in mice in vivo. J. Biol. Chem., 1957, 224, 851.
8. Marks, P. A., and Feigelson, P., The biosynthesis of nucleic acid ribose and of glycogen glucose in the rat. J. Biol. Chem., 1957, 226, 1001.

9. Bernstein, I. A., Synthesis of ribose by the chick. J. Biol. Chem., 1953, 205, 317.

10. Muntz, J. A., and Murphy, J. R., Pathways of glucose metabolism in rat liver, in vivo. Federation Proc., 1955, 14, 258.

11. Chambers, W. H., Undernutrition and carbohydrate metabolism. Physiol. Rev., 1938, 18, 248.

12. Lundbaek, $K$., Metabolic abnormalities in starvation diabetes. Yale J. Biol. \& Med., 1948, 20, 533.

13. Marks, P. A., and Horecker, B. L., Distribution of radioactive carbon dioxide incorporated into rat liver glycogen. J. Biol. Chem., 1956, 218, 327.

14. Stetten, D., and Boxer, G. E., Studies in carbohydrate metabolism. J. Biol. Chem., 1944, 155, 231.

15. Topper, Y. J., and Hastings, A. B., A study of the clinical origins of glycogen by the use of $\mathrm{C}^{16}-12$ beled carbon dioxide, acetate, and pyruvate. J. Biol. Chem., 1949, 179, 1255.

16. Somogyi, M., A new reagent for the determination of sugars. J. Biol. Chem., 1945, 160, 61.

17. Gunsalus, I. C., and Gibbs, M., The heterolactic fermentation. II. Position of $\mathrm{C}^{\mathrm{t}}$ in the products of glucose dissimilation by Leuconostoc mesenteroides. J. Biol. Chem., 1952, 194, 871.

18. Horecker, B. L., and Mehler, A. H., Carbohydrate metabolism. Ann. Rev. Biochem., 1955, 24, 207.

19. Korkes, S., Carbohydrate metabolism. Ann. Rev. Biochem., 1956, 25, 685.

20. Marks, P. A., A newer pathway of carbohydrate metabolism; the pentose phosphate pathway. Diabetes, 1956, 5, 276 .

21. Wood, H. G., The synthesis of liver glycogen in the rat as an indicator of intermediary metabolism. Cold Spring Harbor Symp. on Quant. Biol., 1948, 13, 201.

22. Cook, M., and Lorber, V., Conversion of 1-C $\mathrm{C}^{3 \mathrm{t}}$-mannose and 1-C'-glucose to liver and muscle glycogen in the intact rat. J. Biol. Chem., 1952, 199, 1.

23. Hers, H. G., The conversion of fructose-1- $\mathrm{C}^{24}$ and sorbitol-1-C $\mathrm{C}^{16}$ to liver and muscle glycogen in the rat. J. Biol. Chem., 1955, 214, 373. 